\title{
Influence of Deformation Degree and Cooling Rate on Microstructure and Phase Transformation Temperature of B1500HS Steel
}

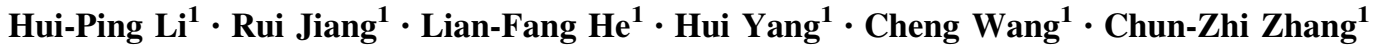

Received: 22 November 2016/Revised: 11 April 2017/Published online: 19 May 2017

(C) The Chinese Society for Metals and Springer-Verlag Berlin Heidelberg 2017

\begin{abstract}
To study the effects of the deformation degree and cooling rate on the microstructure and phase transformation temperature for the $\mathrm{B} 1500 \mathrm{HS}$ steel, the samples were heated at $900{ }^{\circ} \mathrm{C}$ for $5 \mathrm{~min}$, compressed by $10,20,30$ and $40 \%$ at the strain rate of $0.1 \mathrm{~s}^{-1}$, and then cooled down at the rates of $50,40,25,20$ and $15{ }^{\circ} \mathrm{C} / \mathrm{s}$ by the thermo-mechanical simulator, respectively. The start and finish temperatures of the phase transformation were determined by the tangent method, and the volume fraction of the phase transformation was ascertained by the level principle according to the dilatometric curves. The volume fraction of the retained austenite was determined by X-ray diffraction. The results show that the volume fraction of the bainite rises with an increase in the deformation degree as the cooling rate is lower than the critical rate. At the same cooling rate, the phase transformation temperature rises with an increase in the deformation degree, and the sizes of both the martensite and bainite phases reduce due to the austenite grain refinement induced by the deformation. The volume fraction of the retained austenite reduces as the deformation degree increases. The critical cooling rate of the undeformed samples is approximately $25^{\circ} \mathrm{C} / \mathrm{s}$ and the critical cooling rate rises as the deformation degree increases.
\end{abstract}

\section{KEY WORDS: Deformation; Cooling rate; Microstructure; Phase transformation temperature}

\section{Introduction}

By using advanced high-strength steels (AHSS) and ultrahigh-strength steels (UHSS) in the body in white (BIW) of cars, the car's safety, reliability and comfort can be greatly improved. Moreover, the energy consumption and the weight of the BIW can also be reduced remarkably, whereas most of the AHSS and UHSS sheets have a poor formability at room temperature due to the high tensile

Available online at http://link.springer.com/journal/40195.

Hui-Ping Li

lihuiping99@163.com

$\triangle$ Lian-Fang $\mathrm{He}$

lf_he2007@126.com

1 School of Materials Science and Engineering, Shandong University of Science and Technology, Qingdao 266590, China strength, and certain defects (cracking, corrugation, springback) can easily be produced in the workpiece of sheet cold forming [1]. In order to meet the requirements of the BIW for UHSS sheets, hot stamping for the quenchable boron steel sheets is presented and developed to improve the formability of the UHSS sheets. The hot stamping technology combines both the sheet metal forming and the quenching process, greatly improving the forming performance and the mechanical properties of the UHSS. At present, there are two types of hot stamping processes; the direct hot stamping process is mainly used in the produced workpiece with the smaller deformation and simple shape, and the indirect hot stamping is mainly used in the produced workpiece with the deep drawing and complex shape [2].

Hot stamping is a really effective technology which can completely avoid the cracking and wrinkling of the UHSS sheets by using selection and optimization of the technological parameters of forming. The avoidance of the 
workpiece defects in the hot stamping process was studied by some researchers with the use of the forming limit diagram [3] and constitutive equations [4] of the UHSS at an elevated temperature. Moreover, hot stamping can be used for the formation of the components with distributed microstructure and mechanical properties (different microstructure and mechanical properties in different region) [5]. The comprehensive mechanical properties (high tensile strength and good deformation energy absorption) of the B-pillar in the BIW of cars can be significantly improved, as the microstructure of the ferrite and pearlite having been transformed from austenite at the lower cooling rate and having the lower tensile strength is produced at the special region of B-pillar in the hot stamping process [6]. Reductions of the cooling rate at the special region can be performed by the use of the thin air gap between the hot stamping tools and the UHSS sheets [7], the heating of the hot stamping tools and the increase of the surface temperature of the special region [8], the use of the metal with the lower thermal conductivity [9] or the use of a lower pressure between the hot stamping tools and the UHSS sheets [10].

As far as the design of hot stamping tools and the components with the distributed mechanical properties is concerned, it has become necessary and practical to research the effect of the deformation degree and cooling rate on the start temperature of the phase transformation, microstructure and micro-hardness. In the hot stamping process, the deformation at an elevated temperature can change the microstructure of the austenite and affect the subsequent corresponding phase transformation behavior, the microstructure evolution of new phases and the corresponding final mechanical properties of the hot stamping parts.

In this paper, the boron steel of B $1500 \mathrm{HS}$ by the thermal-mechanical simulator Gleeble-1500D was studied. The samples were heated to $900{ }^{\circ} \mathrm{C}$ at the rate of $10{ }^{\circ} \mathrm{C} / \mathrm{s}$ and retained at the temperature of $900{ }^{\circ} \mathrm{C}$ for $5 \mathrm{~min}$ for full austenitization of the samples. Furthermore, the samples were compressed at the strain rate of $0.1 \mathrm{~s}^{-1}$ along the axial direction and the deformation degrees for different samples were designed at $0,10,20,30$ or $40 \%$. Following the compression, the samples were cooled down to room temperature with the different cooling rates, respectively. The effects of the deformation degree and cooling rate on the phase transformation temperature, microstructure and micro-hardness, were studied. Moreover, the volume fraction of phase transformation product was ascertained by the level principle according to the dilatometric curves, and the volume fraction of the retained austenite was determined by X-ray diffraction. The effect of the deformation degree on the grain size of the austenite was also studied.

\section{Experimental}

The chemical composition (wt $\%$ ) of the B1500HS steel measured by the optical emission spectrometer ARL3460 is $0.23 \mathrm{C}, 0.25 \mathrm{Si}, 1.35 \mathrm{Mn}, 0.19 \mathrm{Cr}, 0.04 \mathrm{Mo}, 0.03 \mathrm{Ti}$, $0.003 \mathrm{~B}, 0.004 \mathrm{~V}, 0.015 \mathrm{P}, 0.006 \mathrm{~S}$ and the remaining percentage for $\mathrm{Fe}$. The size of the samples was $\Phi 8 \mathrm{~mm} \times 12 \mathrm{~mm}$.

Moreover, with the thermal-mechanical simulator Gleeble-1500D, the samples were heated up to $900{ }^{\circ} \mathrm{C}$ by the heating rate of $10{ }^{\circ} \mathrm{C} / \mathrm{s}$ and retained at the temperature of $900{ }^{\circ} \mathrm{C}$ for $5 \mathrm{~min}$ in order to achieve full austenitization. Subsequently, the samples were compressed at the strain rate of $0.1 \mathrm{~s}^{-1}$ and the deformation degrees for different samples were $0,10,20,30$ or $40 \%$. Following compression, the samples were cooled down to room temperature at the cooling rates of $50,40,25,20$ and $15^{\circ} \mathrm{C} / \mathrm{s}$, respectively. During the experimental process, thermocouples were used for measurement of the temperature. The cooling rate can be controlled according to the measured temperature during testing. The schematic diagram of the experimental procedure is shown in Fig. 1, and 25 samples were tested in the mentioned executed experiments.

Moreover, the compressed samples were cut into two parts along the compression direction by the wire-cut electrical discharge machining process. Both sections of the samples were polished by the mechanical polishing apparatus and etched by a $4 \%$ nitric acid alcohol solution. The microstructure was observed and analyzed by both an optical microscope (NIKON ME600) and a high-resolution scanning electron microscope (FEI, Nova NanoSEM 450). The micro-hardness was measured by a micro-Vickers hardness tester (FM-700/SVDM4R). The volume fraction of retained austenite was analyzed by an X-ray diffraction analyzer (D/MAX-2200).

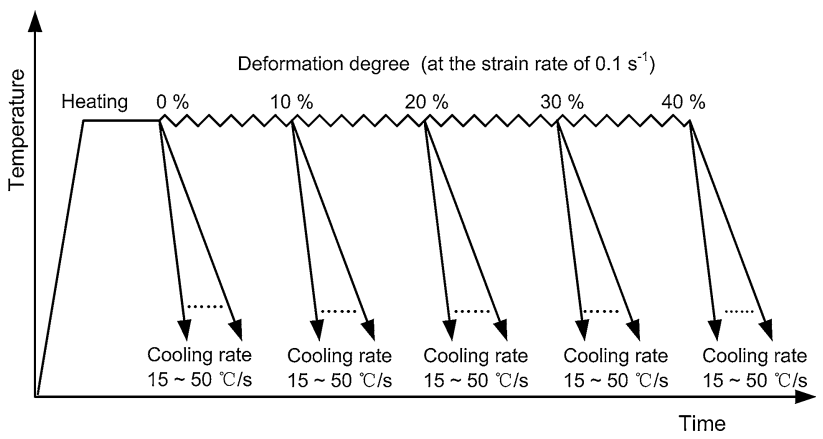

Fig. 1 Schematic diagram of experiment 


\section{Results and Discussion}

\subsection{Temperature}

The observed dilatometric curves along the radial direction are recorded during the cooling process by the strain gauge device. The start and finish temperatures of phase transformation for the B1500HS steel can be obtained by the tangent method according to the dilatometric curves under different testing conditions as shown in Fig. 2.

The dilatometric curves measured by the simulator Gleeble-1500D are shown in Fig. 3. According to the aforementioned dilatometric curves, both the Ms and Mf temperatures can be attained by the tangent method shown in Fig. 2.

The curves shown in Fig. 3a display that at the cooling rate of $50{ }^{\circ} \mathrm{C} / \mathrm{s}$, the Ms temperatures are approximately $389,396,399,400$ and $404{ }^{\circ} \mathrm{C}$ for the samples with relative deformation $0,10,20,30$ and $40 \%$ and the Mf temperatures are $267,268,271,273$ and $277{ }^{\circ} \mathrm{C}$ approximately. The curves shown in Fig. $3 \mathrm{~b}$ display that at the cooling rate of $40{ }^{\circ} \mathrm{C} / \mathrm{s}$, the Ms temperatures are approximately $388,399,400,402$ and $405{ }^{\circ} \mathrm{C}$ for the samples with relative deformation $0,10,20,30$ and $40 \%$, whereas the Mf temperatures are 270, 272, 274, 277 and $278{ }^{\circ} \mathrm{C}$, approximately.

The curves shown in Fig. 3c display that at the cooling rate of $25{ }^{\circ} \mathrm{C} / \mathrm{s}$, both $\mathrm{Ms}$ and $\mathrm{Mf}$ temperatures rise with an increase in the deformation degree when the latter is in the $0-20 \%$ range. When the deformation degree exceeds $30 \%$, the trend of dilatometric curve is different from that of the corresponding degree of the other curves. There are three points of tangency in the dilatometric curves: the first is located in the $400-450{ }^{\circ} \mathrm{C}$ temperature range, the second in the $350-400{ }^{\circ} \mathrm{C}$ temperature range and the third is close to $250{ }^{\circ} \mathrm{C}$. It is interpreted that two types of phase transformation occur during the cooling process as the deformation degree is in the $30-40 \%$ range. The temperature at the first point of tangency is the Bs temperature, which are 413 and $426{ }^{\circ} \mathrm{C}$, respectively, for the samples with the deformation degrees of 30 and $40 \%$. The temperature at the second point of tangency is the bainite finish (Bf) and Ms temperature simultaneously, which are 385 and $382{ }^{\circ} \mathrm{C}$, respectively, for the samples with the deformation degrees of 30 and $40 \%$. The temperature at the third point of tangency is the Mf temperature, which are 272 and $274{ }^{\circ} \mathrm{C}$, respectively, for the samples with the deformation degrees of 30 and $40 \%$. Concerning the samples with the deformation degree over $30 \%$, the Ms temperature (or Bf temperature) is reduced during the increase of the deformation degree. In addition, the Mf temperature is increased greatly, due to the bainitic transformation induced by deformation at the cooling rate of $25^{\circ} \mathrm{C} / \mathrm{s}$.

According to the dilatometric curves of the un-deformed samples at the cooling rates of 25,20 and $15{ }^{\circ} \mathrm{C} / \mathrm{s}$, the phase transformation temperatures of both martensite and bainite can be determined by the tangent method shown in Fig. 2. The dilatometric curves shown in Fig. 4 display that as the cooling rate remains at $25^{\circ} \mathrm{C} / \mathrm{s}$, the trend of the dilatometric curve does not change before the martensitic transformation, although a slight variation is produced in the dilatometric curve at the cooling rate of $20^{\circ} \mathrm{C} / \mathrm{s}$ and a significant variation is produced in the dilatometric curve at the cooling rate of $15{ }^{\circ} \mathrm{C} / \mathrm{s}$. The variation indicates that the bainitic transformation is primarily produced during the cooling process of the B1500HS samples. The Bs temperatures are approximately 511 and $519{ }^{\circ} \mathrm{C}$, respectively, at the cooling rate of 20 and $15{ }^{\circ} \mathrm{C} / \mathrm{s}$. Therefore, the curves shown in Figs. 3 and 4 indicate that the critical cooling rate is approximately $25{ }^{\circ} \mathrm{C} / \mathrm{s}$ for the un-deformed samples of the B1500HS steel to obtain an almost full martensite phase structure during the quenching process, and the critical cooling rate is increased for the deformed samples. In other words, the deformation can result in the increase of the critical cooling rate of the B1500HS steel to obtain an almost full martensite phase structure.
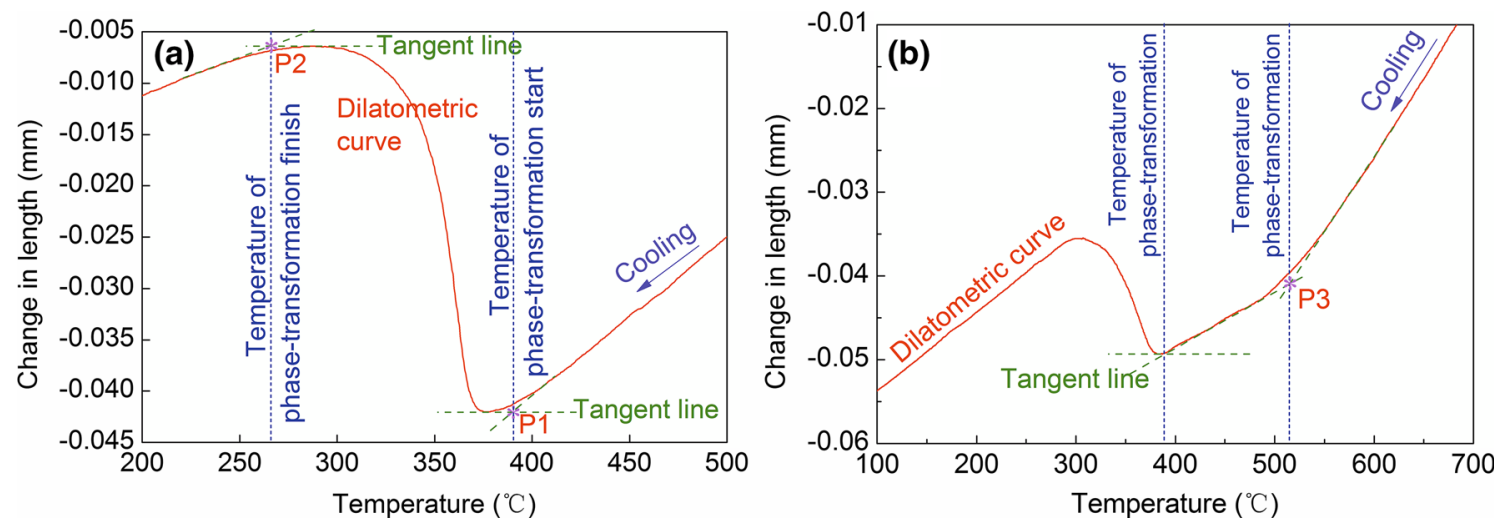

Fig. 2 Schematic diagram ascertaining the start and finish temperatures of phase transformation by the tangent method 

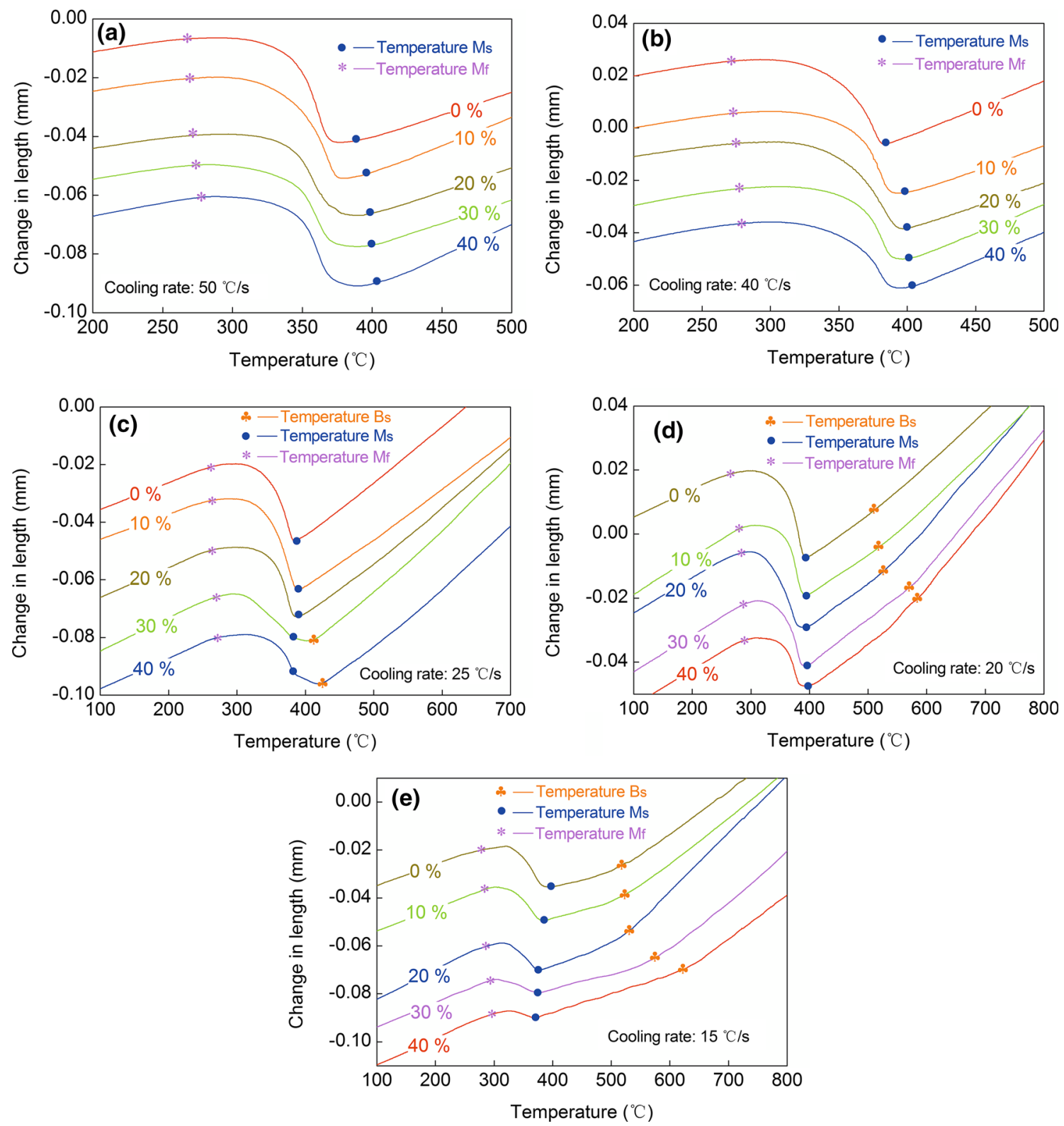

Fig. 3 Dilatometric curves of B1500HS samples subjected to different deformation degree. a At the cooling rate of $50{ }^{\circ} \mathrm{C} / \mathrm{s}$; $\mathbf{b}$ at the cooling rate of $40{ }^{\circ} \mathrm{C} / \mathrm{s}$; $\mathbf{c}$ at the cooling rate of $25{ }^{\circ} \mathrm{C} / \mathrm{s}$; $\mathbf{d}$ at the cooling rate of $20^{\circ} \mathrm{C} / \mathrm{s}$; $\mathbf{e}$ at the cooling rate of $15{ }^{\circ} \mathrm{C} / \mathrm{s}$

As the cooling rate is not lower than the critical cooling rate of B1500HS steel, both the Ms and Mf temperatures can be attained by the dilatometric curves shown in Fig. 3. The Ms and Mf temperatures of the samples with different cooling rates and deformation degrees are shown in Fig. 5a, b. As the cooling rate is lower than the critical cooling rate, the Ms, Mf and Bs temperatures of the samples with different cooling rates and deformation degrees are shown in Fig. 6.

The curves shown in Fig. 5 display that when the sample cooling rates remain at 50 and $40{ }^{\circ} \mathrm{C} / \mathrm{s}$, both the Ms and Mf temperatures increase as the deformation degree increases, and the Ms temperature variations are in the $7-17{ }^{\circ} \mathrm{C}$ range, whereas the $\mathrm{Mf}$ temperature variations are in the
8-10 ${ }^{\circ} \mathrm{C}$ range. As the cooling rate is not lower than the critical cooling rate of $\mathrm{B} 1500 \mathrm{HS}$ steel, the deformation has a slight effect on the Ms and Mf temperatures. It is in a qualitative agreement with earlier observations of both the compressive and the tensile stresses resulting in an increase of the Ms temperature [11]. In addition, Barcellona et al. [12] investigated the uniaxial tensile test of $22 \mathrm{MnB} 5$ steel at $800{ }^{\circ} \mathrm{C}$ considering two prestrain values equal to 8 and $17 \%$, and found that the Ms temperature variation is approximately $10^{\circ} \mathrm{C}$ the $\mathrm{Mf}$ temperature variation is approximately $20^{\circ} \mathrm{C}$.

Moreover, the curves shown in Fig. 5 display that for the samples quenched at the cooling rate of $25^{\circ} \mathrm{C} / \mathrm{s}$, the 


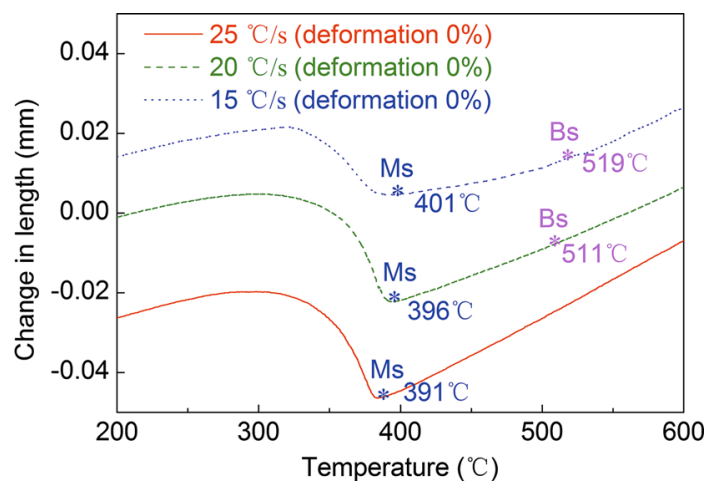

Fig. 4 Dilatometric curves of un-deformed samples at cooling rates of 25,20 and $15{ }^{\circ} \mathrm{C} / \mathrm{s}$

deformation also has a slight effect on both the Ms and Mf temperatures, as the deformation degree is lower than $20 \%$. However, as the deformation degree increases, the Ms temperature (or Bf temperature) reduces obviously and the Mf temperature increases slightly due to the bainitic transformation induced by the deformation, as the deformation degree is not lower than $20 \%$. The decrease in the Ms temperature is approximately $10{ }^{\circ} \mathrm{C}$, the increase in the Mf temperature is approximately $8^{\circ} \mathrm{C}$. The reason for the Ms temperature reduction is attributed to a carbon enrichment in the un-transformed austenite, as a consequence of bainitic ferrite formation, consequently transforming into lath martensite at a lower temperature. Naderi et al. [13] investigated the uniaxial compression test of $27 \mathrm{MnCrB} 5$ steel at $600-850{ }^{\circ} \mathrm{C}$ with the different strain rates between $0.1-1.0 \mathrm{~s}^{-1}$ and found that the decrease in the Ms temperature is approximately $15^{\circ} \mathrm{C}$ owing to martensite content reduction, the increase in the $\mathrm{Mf}$ temperature is approximately $50{ }^{\circ} \mathrm{C}$. For the hot-rolled plate of $22 \mathrm{MnB} 5$ steel, Nikravesh et al. [14] found that the Ms temperature in a hot deformed condition is lower than that in an un-deformed state at the cooling rate less than $15^{\circ} \mathrm{C} / \mathrm{s}$, the decrease in Ms temperature is in the range of $10-13{ }^{\circ} \mathrm{C}$.

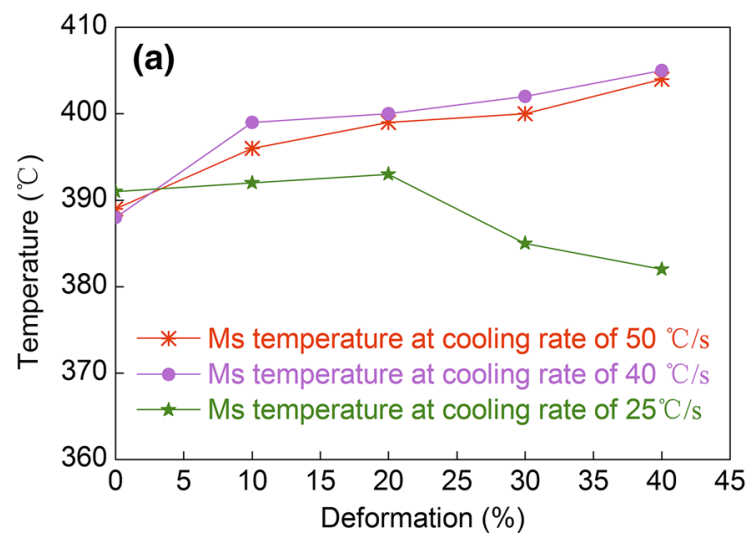

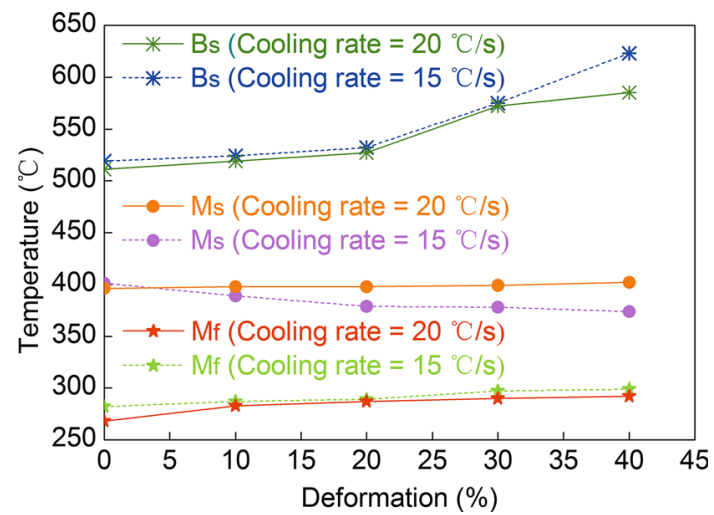

Fig. 6 Transformation temperatures of martensite and bainite at cooling rates of 20 and $15^{\circ} \mathrm{C} / \mathrm{s}$ (Ms martensite start temperature, $M f$ martensite finish temperature, $B s$ bainite start temperature)

However, Nikravesh et al. [14] gave an opposite tendency for the Mf temperature. They found that the Mf temperature in a hot deformed condition is lower than that in an undeformed state, and the decrease in Mf temperature is in the range of $10-20{ }^{\circ} \mathrm{C}$.

\subsection{Grain Size of the Austenite}

The samples were polished by the mechanical polishing apparatus and etched with the saturated water solution of picric acid in a water bath at the temperature of $80^{\circ} \mathrm{C}$. In order for the observed grain boundary to be obtained, the polishing and etching process were repeated several times. The metallographic images shown in Fig. 7 were taken by the Nikon ME600 metallographic microscope.

As the B1500HS steel contains a low percentage of titanium, vanadium and other alloy elements, it is capable of inducing the precipitation of the second phase [such as Ti(N, C), (Ti, V)(N, C), V(N, C)] during deformation [15]. Moreover, the deformation can result in dislocation. When

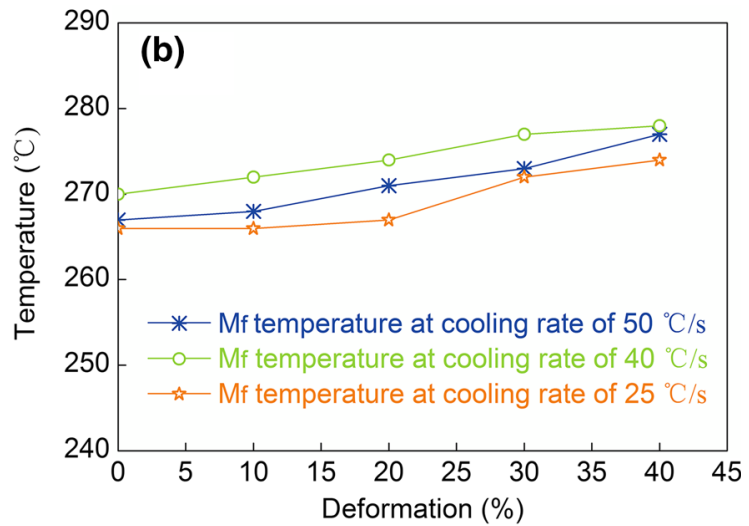

Fig. 5 Transformation temperature of martensite at cooling rates of 50,40 and $25{ }^{\circ} \mathrm{C} / \mathrm{s}(M s$ martensite start temperature, $M f$ martensite finish temperature): a Ms temperature; b Mf temperature 

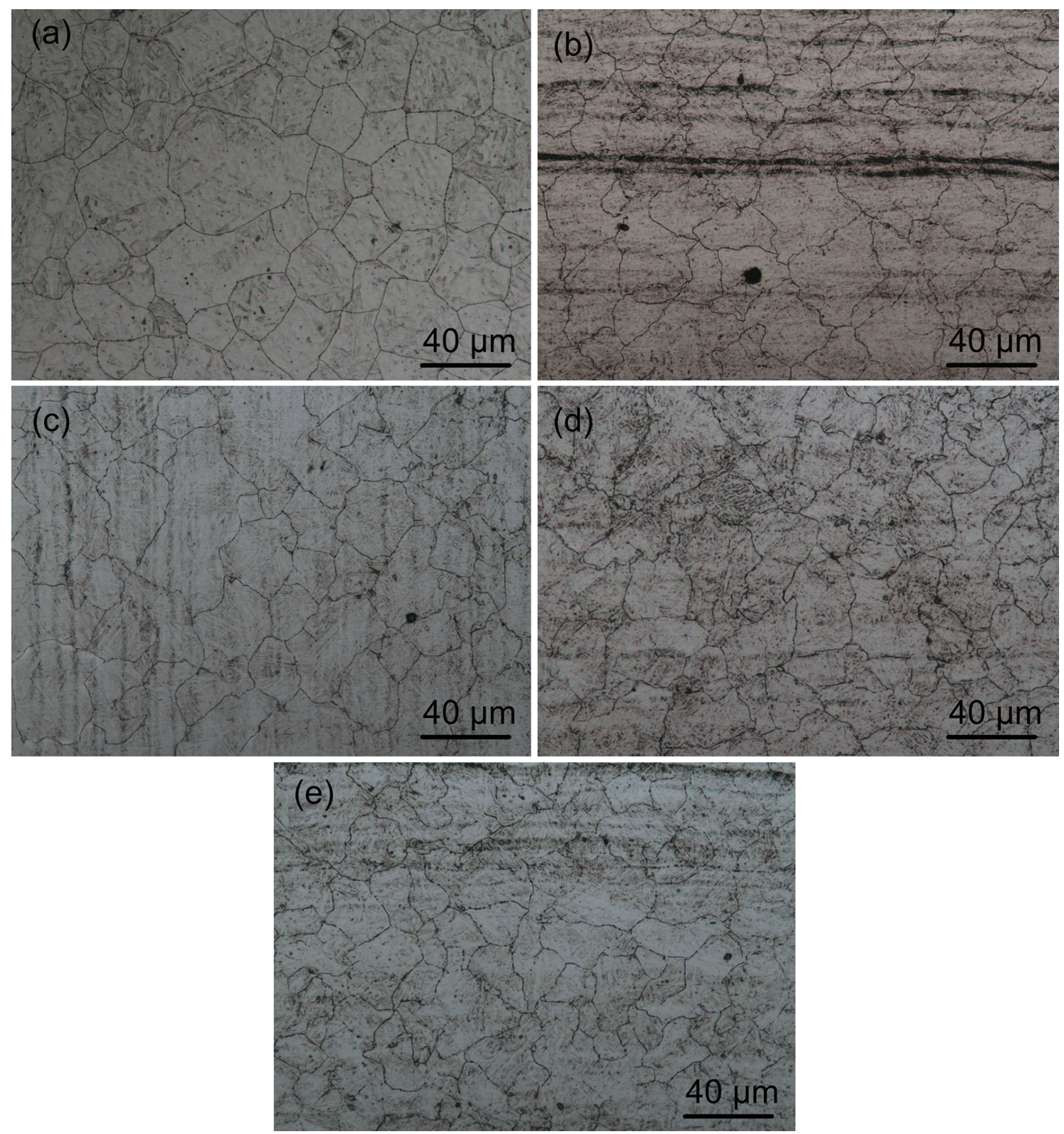

Fig. 7 Metallographic images taken by the Nikon ME600 metallographic microscope: a un-deformed sample; b sample subjected to $10 \%$ deformation degree; c sample subjected to $20 \%$ deformation degree; d sample subjected to $30 \%$ deformation degree; e sample subjected to $40 \%$ deformation degree

the deformation degree is in the $20-40 \%$ range [16], the great number of dislocations is pinned at the precipitates, contributing as an important role to the austenite grain boundary pinning, and the grain boundary displays an irregular state, as shown in Fig. 7b-e.

The grain size is calculated by the mean linear intercept method. The length of the certain line and the number of intersection points at this line are used for the average intercept calculation according to Eq. (1) and then the grain lever relative to this line can be calculated using Eq. (2) and the average intercept. Finally, the average grain level can be obtained according to Eq. (3).
$I_{i}=L_{i} /\left(m \times p_{i}\right)$.

$G_{i}=\left(-6.643856 \times \lg I_{i}\right)-3.288$.

$G_{\mathrm{a}}=\frac{1}{n} \sum_{i=1}^{n} G_{i}$.

where $I_{i}$ is the average intercept (unit, $\mathrm{mm}$ ) relative to the $i$ th line, $L_{i}$ is the length of the $i$ th line (unit, $\mathrm{mm}$ ), $m$ is the amplification factor, $p_{i}$ is the number of intersection points relative to the $i$ th line, $G_{i}$ is the grain level relative to the $i$ th line, $G_{\mathrm{a}}$ is the average grain level, $n$ is the number of line. 
According to the metallographic images shown in Fig. 7 and Eqs. (1)-(3), the effect of the deformation degree on the grain size of the austenite can be attained as shown in Fig. 8. It is shown that the average grain size of the austenite reduces as the deformation degree increases. The dynamic recrystallization does not take place as the thermal deformation degree is $10 \%$ and the grain sizes of the austenite are approximately 22.0 and $21.6 \mu \mathrm{m}$ for the samples with no deformation and $10 \%$ deformation, respectively, whereas the grain size of the austenite has no obvious alteration. As the thermal deformation degree is over $20 \%$, the dynamic recrystallization begins to take place and the grain size decreases. The grain sizes of the austenite are approximately 19.9, 16.7 and $16.2 \mu \mathrm{m}$ for the samples with the 20,30 and 40\% deformation degree, respectively.

\subsection{Microstructure}

The microstructures of the samples with the $50{ }^{\circ} \mathrm{C} / \mathrm{s}$ cooling rate are shown in Fig. 9. For the steels with a low carbon content $(<0.6 \%)$, the formation temperature of the martensite is more than $200{ }^{\circ} \mathrm{C}$, lath martensite appears. For the steels with high carbon content $(>1.0 \%)$, the formation temperature of the martensite is less than $200{ }^{\circ} \mathrm{C}$, subsequently leading the martensite to form a plate-like structure [17]. Lath martensite is generally formed in various packets inside the austenite grain. The morphologies of the lath martensite appear to be the packets, blocks, subblocks, and laths. The packet is a group of blocks with the same habit plane, whereas a block contains laths with the same orientation [18]. The orientation relationship between lath martensite and austenite can be characterized by the Kurdyumov-Sachs (K-S), relation as follows: $(011)_{\mathrm{M}} / /$ $(111)_{\mathrm{A}},(111)_{\mathrm{M}} / /(011)_{\mathrm{A}}[19,20]$, and also shown in Fig. 10.

The dilatometric curves of the B1500HS shown in Fig. 3 display the Mf temperature is higher than $200{ }^{\circ} \mathrm{C}$ under the

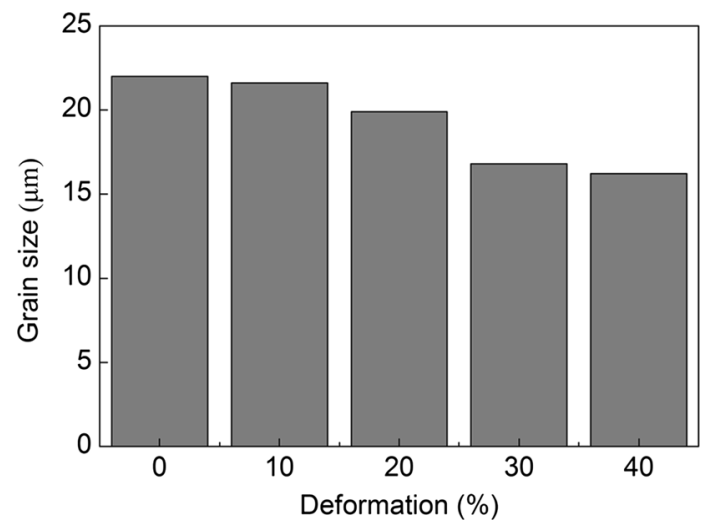

Fig. 8 Effects of deformation degree on the grain size of austenite cooling rate being $50{ }^{\circ} \mathrm{C} / \mathrm{s}$. Microstructure in Fig. 9a shows that the orientation relationship of laths is approximately $60^{\circ}$ or $120^{\circ}$. Moreover, the B1500HS steel is a type of a low-carbon alloy steel with a carbon content of approximately $0.23 \%(<0.6 \%)$. Therefore, the microstructure of the B1500HS samples at the cooling rate of $50{ }^{\circ} \mathrm{C} / \mathrm{s}$ displays the lath martensite structure as shown in Fig. 9a.

Lath martensite is generally formed in various packets within an austenite grain and does not penetrate the grain boundary of the austenite. A packet contains blocks consisting of laths [21, 22] and the packet size and the block size are considered to be a key factor in the determination of the martensite lath size [23, 24]. Alternatively, the block size may be considered to be the 'grain size' of the martensite [23]. A number of dislocations produced during deformation combined with the fine second phase particles precipitated in the grain boundaries and sub-grain boundaries of the austenite, can hinder the grain growth and the grain boundary migration. In addition, a large number of grain boundary defects are produced in the austenite during deformation, delaying martensite growth and refinement. Moreover, the deformation produced at an elevated temperature is proven to be helpful for the recrystallization of the B1500HS steel leading to a grain size refinement of the parent austenite as shown in Figs. 7 and 8. Therefore, the size of the lath martensite decreases as the deformation degree increases as shown in Fig. 9.

The microstructures of the samples at the cooling rate of $40{ }^{\circ} \mathrm{C} / \mathrm{s}$ are similar to the corresponding samples at the cooling rate of $50{ }^{\circ} \mathrm{C} / \mathrm{s}$. At the cooling rate of $25^{\circ} \mathrm{C} / \mathrm{s}$, the microstructure of the samples without deformation, or with the deformation degrees of 10 and $20 \%$, also displays a lath martensite packet as shown in Fig. 11a-c.

When the deformation degree is 30 or $40 \%$, the continuous cooling transformation (CCT) diagram move toward the left due to the deformation. The cooling curve of the $25^{\circ} \mathrm{C} / \mathrm{s}$ cooling rate go through the bainitic transformation zone in the CCT diagrams, leading to a bainitic transformation. A portion of the deformed austenite is transformed into granular bainite and another portion of the austenite is transformed into the bainitic ferrite [25]. The microstructure of the samples consists of a mixed structure including the martensite, the granular bainite (GB) and the bainitic ferrite (BF) as shown in Fig. 11d, e.

The length of the bainitic ferrite laths could be shortened by heavy deformation [26]. As the deformation degree increases, the size of the lath martensite, the lath length and the interval of the bainitic ferrite decrease, as shown in Figs. 11 and 12. The experimental results show that the distance between the laths is approximately $0.83 \mu \mathrm{m}$ and the maximum length of the laths is approximately $12.3 \mu \mathrm{m}$ as the deformation degree is $30 \%$. The distance and the maximum length of the laths are 0.62 and $8.1 \mu \mathrm{m}$, 

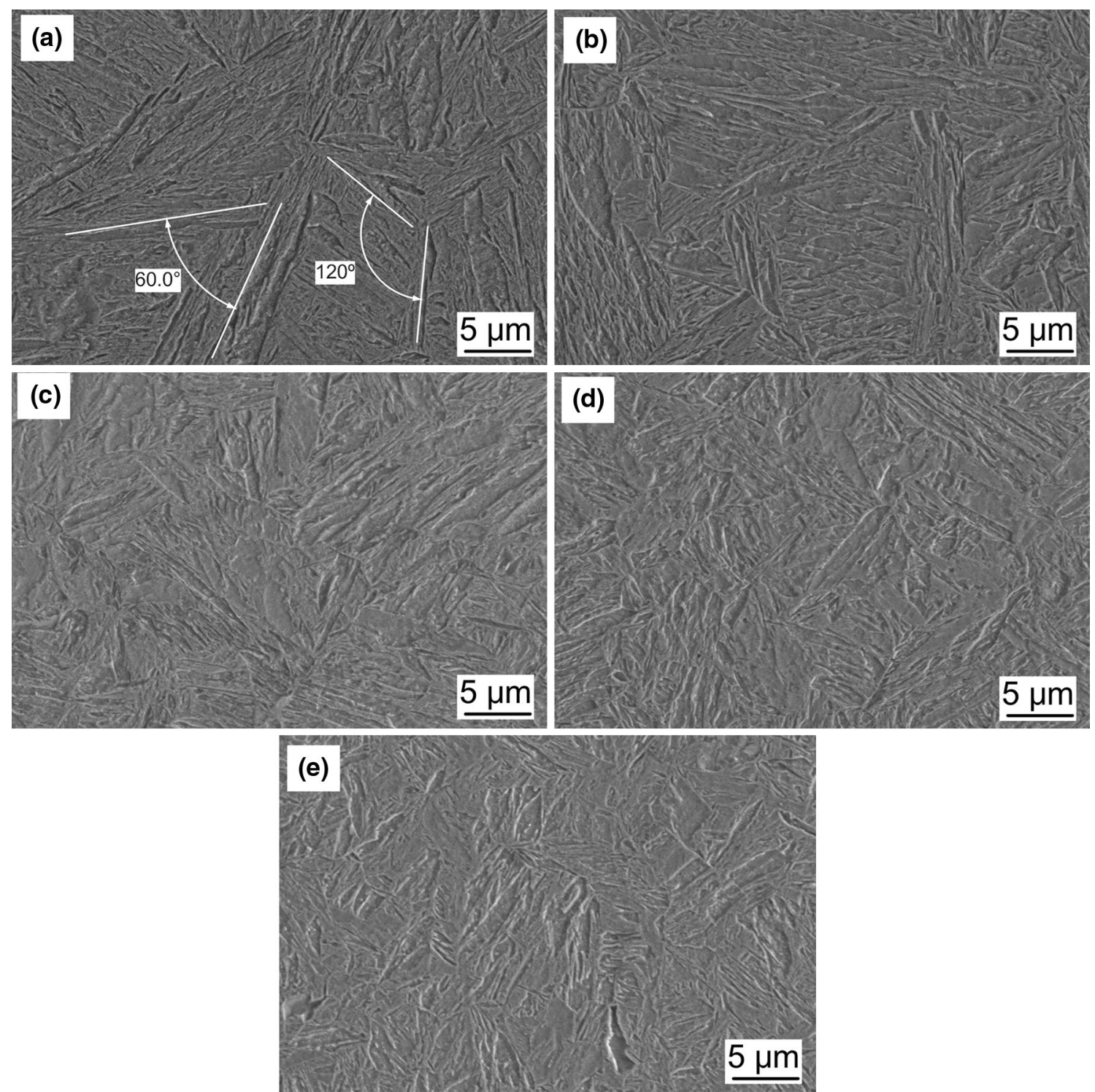

Fig. 9 Microstructures of B1500HS samples subjected to various deformation degrees at the cooling rate of $50{ }^{\circ} \mathrm{C} / \mathrm{s}$ : a $0 \%$; b $10 \%$; c $20 \%$; d $30 \%$; e $40 \%$

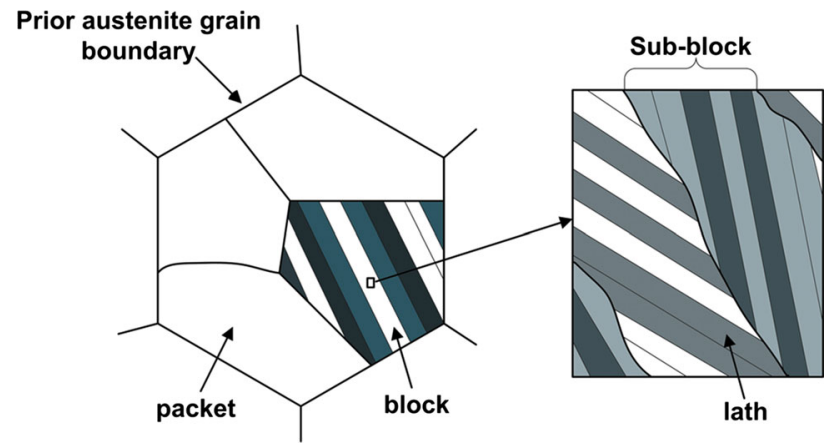

Fig. 10 Schematic illustration of lath martensite [19] respectively, as the deformation degree is $40 \%$ as shown in Fig. 12a, b.

At the cooling rate of $20{ }^{\circ} \mathrm{C} / \mathrm{s}$, the microstructure of the sample is a mixture of lath martensite and lower bainite as shown in Fig. 13. As the deformation degree increases, both the sizes of the martensite and bainite decrease.

At the cooling rate of $15{ }^{\circ} \mathrm{C} / \mathrm{s}$, the microstructure of the sample is a mixture of lath martensite and lower bainite as shown in Fig. 14. As the deformation degree increases, the size of lower bainite decreases due to the refinement of the austenite grain induced by deformation at an elevated temperature. 

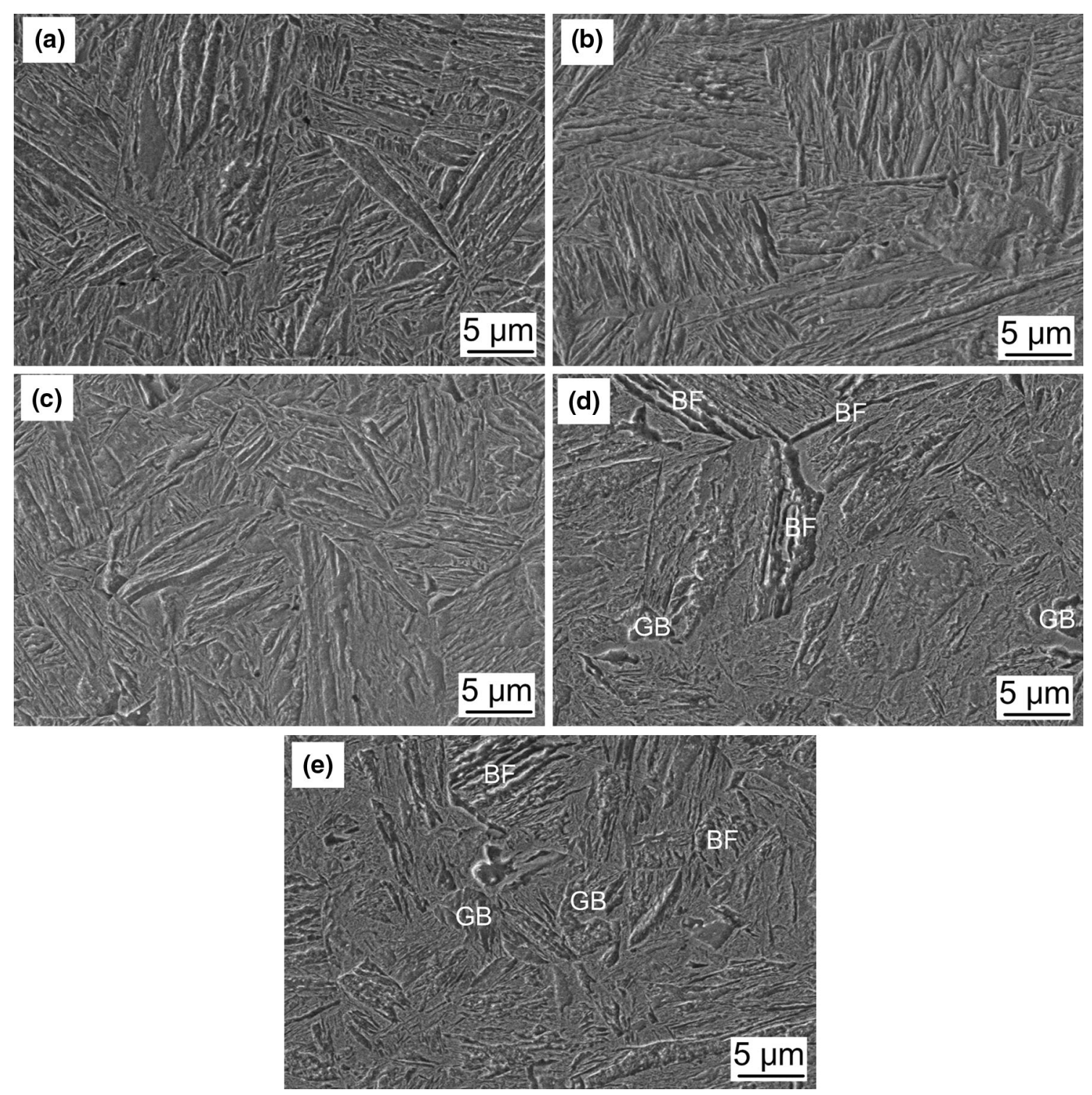

Fig. 11 Microstructures of samples at the $25{ }^{\circ} \mathrm{C} / \mathrm{s}$ cooling rate: a un-deformed sample; $\mathbf{b}$ sample subjected to $10 \%$ deformation degree; $\mathbf{c}$ sample subjected to $20 \%$ deformation degree; $\mathbf{d}$ sample subjected to $30 \%$ deformation degree; e sample subjected to $40 \%$ deformation degree
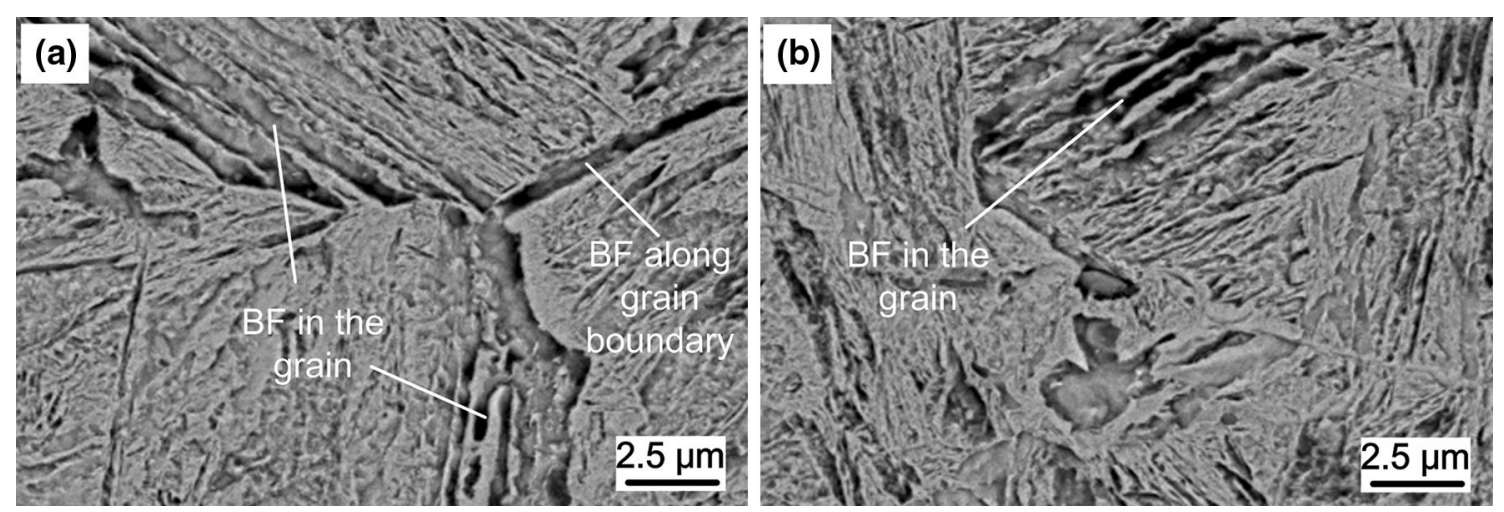

Fig. 12 Microstructures of bainitic ferrite (BF) in samples at the cooling rate of $25{ }^{\circ} \mathrm{C} / \mathrm{s}$ : a sample subjected to $30 \%$ deformation degree; b sample subjected to $40 \%$ deformation degree (the polished samples were etched with a $4 \%$ nitric acid and alcohol solution, and the images were taken using the BSE mode of Nova Nano SEM 450) 

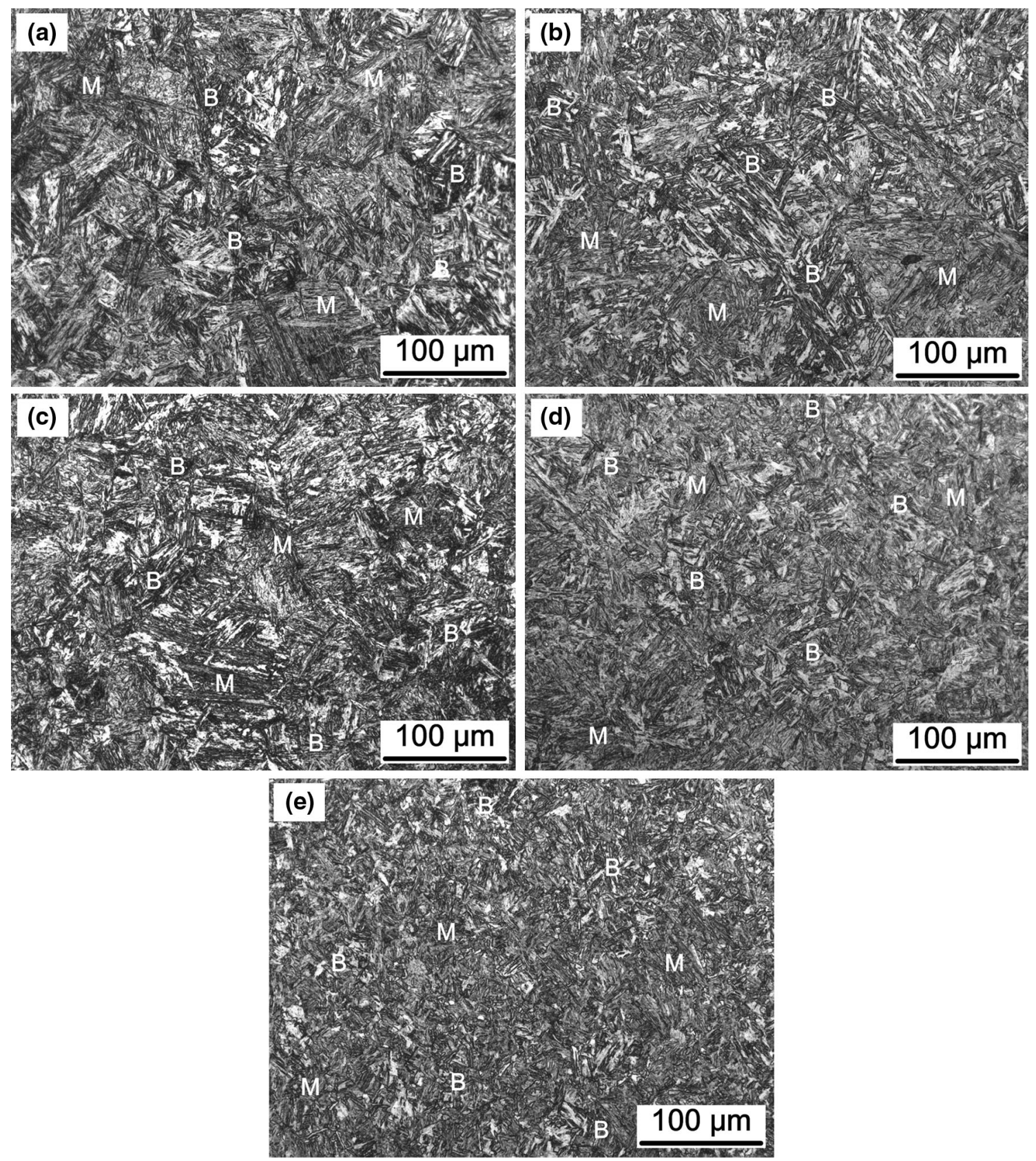

Fig. 13 Microstructures of samples at the cooling rate of $20^{\circ} \mathrm{C} / \mathrm{s}$ : a un-deformed sample; b sample subjected to $10 \%$ deformation degree; c sample subjected to $20 \%$ deformation degree; d sample subjected to $30 \%$ deformation degree; e sample subjected to $40 \%$ deformation degree

\subsection{Volume Fraction of Phase Transformation}

If the cooling rate is less than the critical cooling rate of the B1500HS steel, both the bainite and martensite can be produced in the sample. The dilatometric curve of the undeformed sample at the cooling rate of $15{ }^{\circ} \mathrm{C} / \mathrm{s}$ can be divided into four sections, as shown in Fig. 15. The first section is the dilatometric curve of the austenite, the second section is the dilatometric curve of the austenite being transformed into bainite, provided that the sample temperature ranges from the bainite start (Bs) temperature to the Ms temperature. The third section is the dilatometric curve of the austenite being transformed into martensite, as the sample temperature ranges from the Ms to the Mf temperature. The fourth section is the dilatometric curves of both the martensite and bainite. 

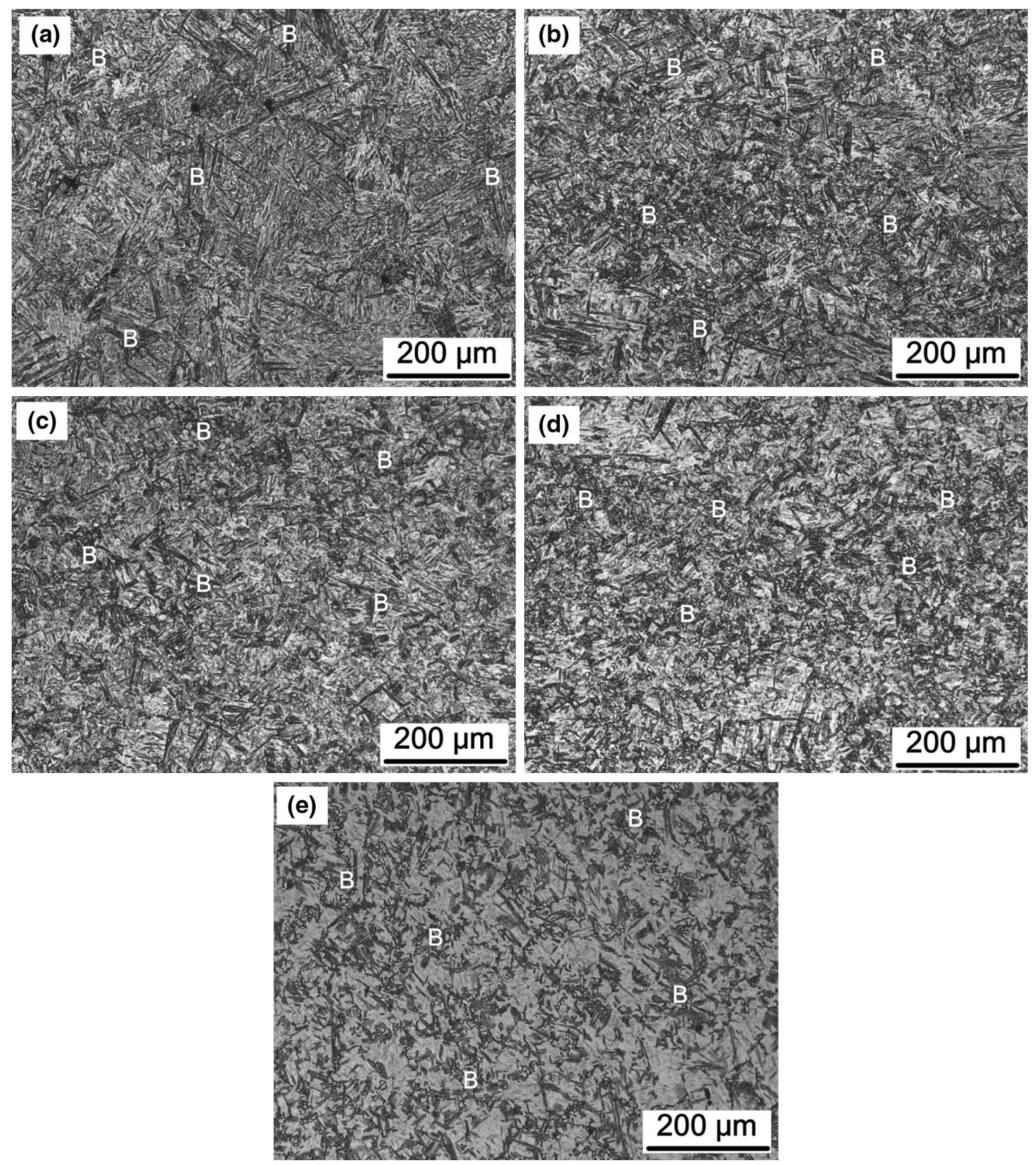

Fig. 14 Microstructures of samples at the cooling rate of $15{ }^{\circ} \mathrm{C} / \mathrm{s}$ : a un-deformed sample; $\mathbf{b}$ sample subjected to $10 \%$ deformation degree; c sample subjected to $20 \%$ deformation degree; d sample subjected to $30 \%$ deformation degree; e sample subjected to $40 \%$ deformation degree

The relationship between the relative volume changes $\Delta V / V_{0}$ and the relative length $\Delta l / l_{0}$ can be expressed as follows [27]

$\frac{\Delta V}{V_{0}}=\frac{3 l_{0}^{2} \Delta l}{V_{0}}=\frac{3 l_{0}^{2} \Delta l}{l_{0}^{3}}=3 \frac{\Delta l}{l_{0}}$.

In Eq. (4) it is shown that the volume change $\Delta V$ of the sample is proportional to the length change $\Delta l$ of the linear expansion. It is interpreted that the volume fraction of both the bainite and martensite formed from austenite in the cooling process could be determined according to the sample length change. A schematic diagram determining the volume fraction of the martensite and bainite by the lever principle is shown in Fig. 15.

Excluding the volume fraction of the retained austenite, the volume fraction of the bainite and martensite in the phase transformation stage (the second and the third stages of the dilatometric curve) can be expressed as follows

$f_{\text {bainite }}=\frac{y}{x+y}=\frac{f_{1}(T)-\left(k_{1} T+p_{1}\right)}{\left(k_{2} T+p_{2}\right)-\left(k_{1} T+p_{1}\right)}$, 


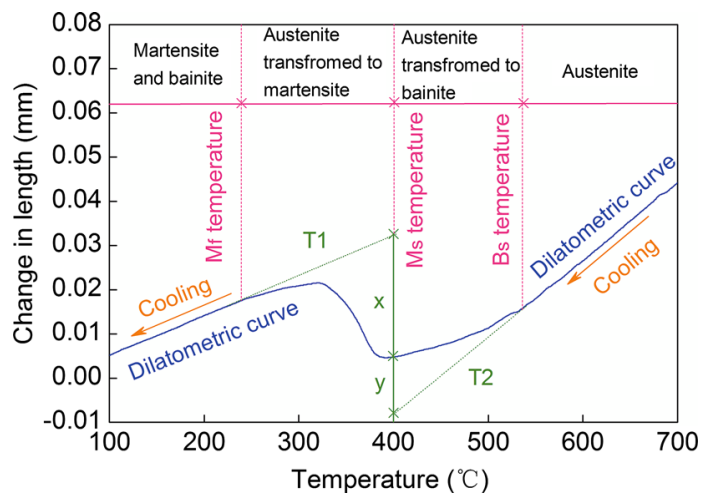

Fig. 15 Determination of the volume fraction of phase transformation by the level principle

$f_{\text {martensite }}=1-\frac{\left(k_{2} T+p_{2}\right)-f_{2}(T)}{\left(k_{2} T+p_{2}\right)-\left(k_{1} T+p_{1}\right)}$,

where $f_{\text {bainite }}$ is the volume fraction of bainite, $f_{\text {martensite }}$ is the volume fraction of martensite, $k_{1}$ and $k_{2}$ are the slope of the tangent $\mathrm{T} 1$ and $\mathrm{T} 2$, respectively, as shown in Fig. 15, $p_{1}$ and $p_{2}$ are the intercepts of the tangent $\mathrm{T} 1$ and $\mathrm{T} 2$ shown in Fig. 15, $f_{1}(T)$ is the function of dilatometric curve and $T$ is temperature.

Using the tangent method and the level principle shown in Figs. 2 and 15, the volume fraction of the bainite for the samples at various cooling rates can be determined according to Eq. (5) as shown in Fig. 16. The samples with the same deformation degree display a rise in the volume fraction of the bainite as the cooling rate is reduced as long as the cooling rate is less than the martensitic critical rate. At the same cooling rate, the volume fraction of the bainite rises as the deformation degree increases. At the cooling rate of $25{ }^{\circ} \mathrm{C} / \mathrm{s}$, the bainite is not produced, while the deformation degree is less than $20 \%$. If the deformation degree surpasses $30 \%$, the bainite is produced.

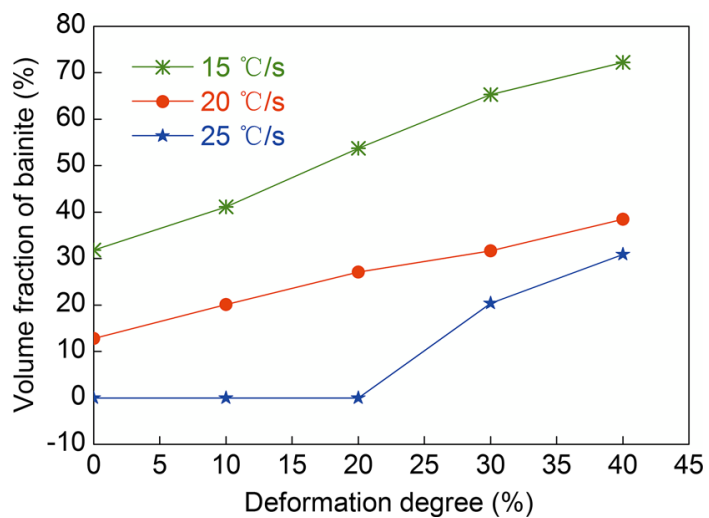

Fig. 16 Volume fraction of bainite for the samples at various cooling rates

\subsection{Micro-Hardness}

A micro-Vickers hardness tester (FM-700/SVDM4R) was used to the hardness measurement. During testing, the load was $200 \mathrm{gf}$ and the holding time of the load was $10 \mathrm{~s}$. The micro-Vickers hardness is shown in Fig. 17. The Vickers micro-hardness of the martensite is a function of the cooling rate and the steel composition [28, 29], which can be characterized by the computation model being

$$
\begin{aligned}
\mathrm{HV}_{\mathrm{M}}= & 127+949 \mathrm{C}+27 \mathrm{Si}+11 \mathrm{Mn}+8 \mathrm{Ni}+16 \mathrm{Cr}+21 \\
& \times \log V_{\mathrm{r}},
\end{aligned}
$$

where $\mathrm{Vr}$ is the cooling rate. $\mathrm{C}, \mathrm{Si}, \mathrm{Mn}, \mathrm{Ni}$ and $\mathrm{Cr}$ are the percentages of corresponding steel compositions. $\mathrm{HV}_{\mathrm{M}}$ is the HV hardness of martensite. In Eq. (6), it is observed that the hardness value of the samples increases as the cooling rate increases at the same deformation degree. This tendency is also shown in Fig. 17.

As the cooling rate is not lower than the critical cooling rate of B1500HS steel, the microstructure is almost fully of the martensite, the micro-Vickers hardness is in the range of $440-490 \mathrm{HV}_{0.2}$. The hardness value decreases as the deformation degree increases due to the microstructure refinement induced by the deformation at the same cooling rate. Abbasi et al. [30, 31] found that the hardnesses of the martensite and bainite are in the range of $400-450 \mathrm{HV}_{0.8}$ and 250-300 $\mathrm{HV}_{0.8}$, respectively. In addition, the results attained by Barcellona et al. [12] and Min et al. [32] display that increasing hot deformation content will result in a lower hardness at the same cooling rate.

At the cooling rate of $25^{\circ} \mathrm{C} / \mathrm{s}$, a certain amount of the bainite is produced as the deformation degree is in the range of $30-40 \%$, leading to the decrease of the hardness. When the cooling rate is lower than the critical cooling rate $\left(25^{\circ} \mathrm{C} / \mathrm{s}\right)$, the hardness is reduced because the volume

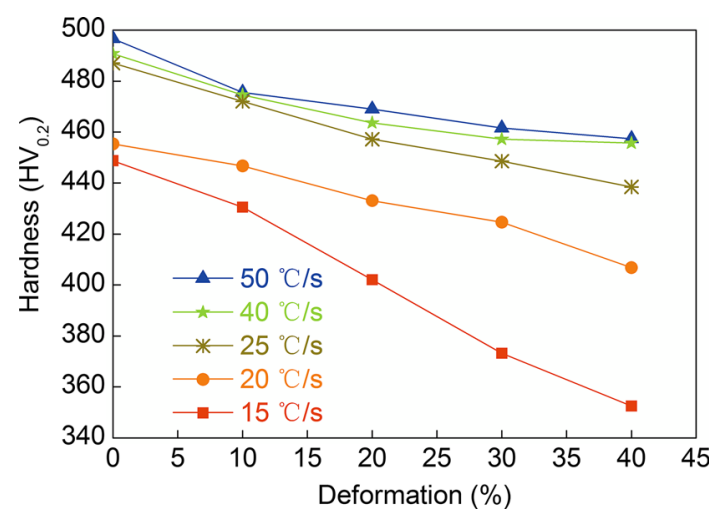

Fig. 17 Micro-Vickers hardness of samples 
fraction of the bainite increases due to the increase of the deformation degree and the reduction in the cooling rate.

\subsection{Retained Austenite}

During the experimental procedure, the retained austenite of the B1500HS sample was analyzed by the X-ray diffraction analyzer (D/MAX-2200) with $\mathrm{Cu} K_{\alpha}$ radiation. The X-ray tube current was $100 \mathrm{~mA}$, the X-ray tube voltage was $40 \mathrm{kV}$, the scanning range was set at $0.5^{\circ}-146^{\circ}$, and the minimum step angle was set at $0.001^{\circ}$.

In order for the accurate measurement of the volume fraction of the retained austenite, the lattice planes (200) and (211) of the martensite, and the lattice planes (200), (220) and (311) of the austenite were scanned and analyzed with the use of the step by step method, the scanning angle was set in the range of $20^{\circ}-110^{\circ}$ and consequently the diffraction angle $2 \theta$ and the integral strength $I$ were determined. The X-ray diffraction powder patterns of the B1500HS samples are shown in Fig. 18, of which the deformation degree is $0,10,20,30$ and $40 \%$, respectively. The volume fraction of the retained austenite are

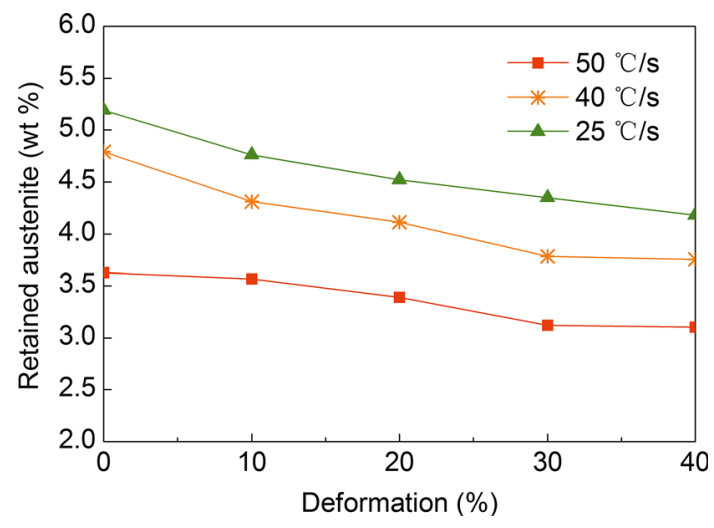

Fig. 19 Volume fraction of the retained austenite in B1500HS samples

determined based on the direct comparison method [33], and the results are shown in Fig. 19.

The curves in Fig. 19 display that both high cooling rates and deformation degrees are helpful for the reduction of the volume fraction of the retained austenite in the samples. At the same cooling rate, the volume fraction of retained austenite decreases with the increase of the
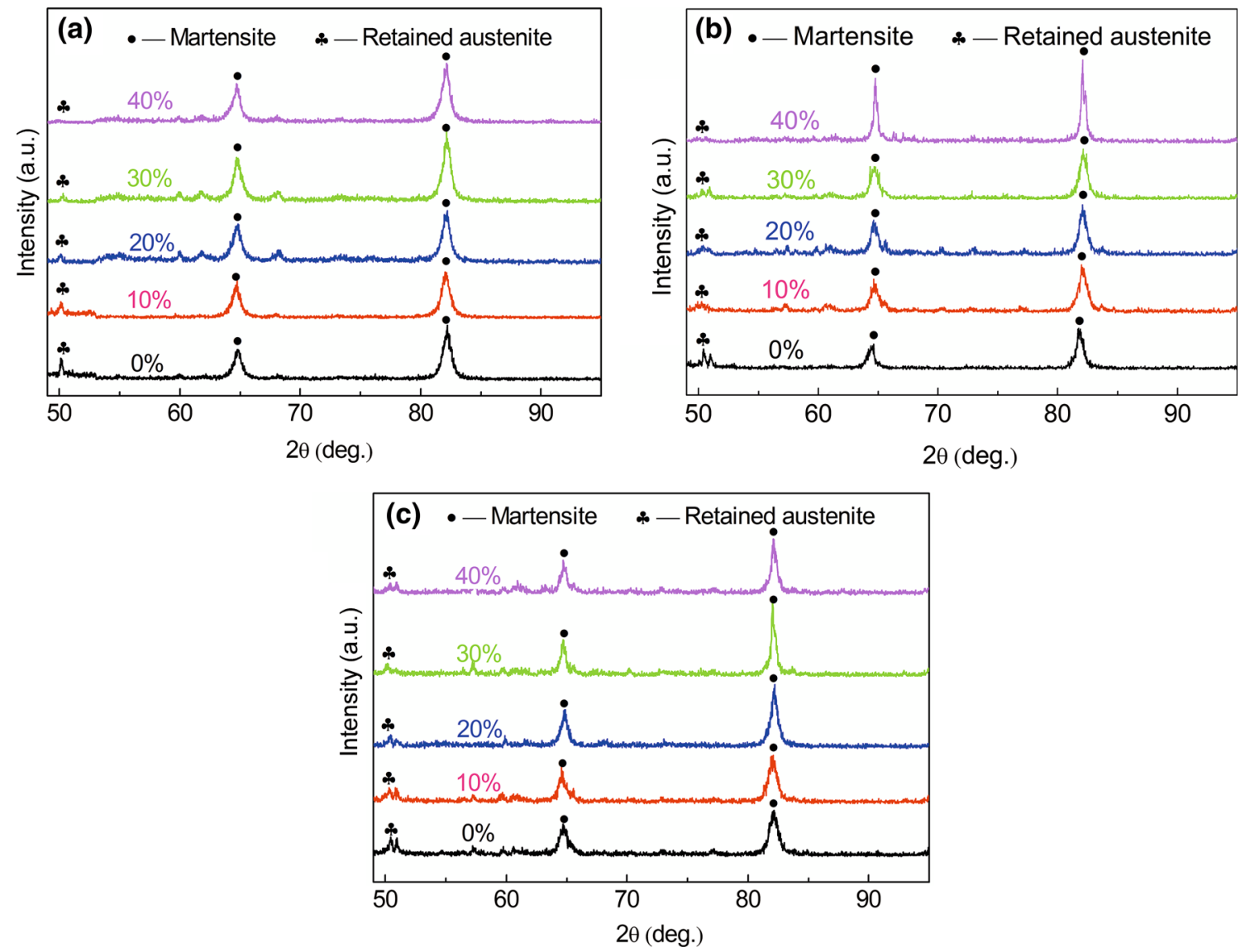

Fig. $18 \mathrm{X}$-ray diffraction powder patterns of samples subjected to the deformation degree of $0,10,20,30$ and $40 \%$ : a At $50{ }^{\circ} \mathrm{C} / \mathrm{s}$ cooling rate; b at $40{ }^{\circ} \mathrm{C} / \mathrm{s}$ cooling rate; c at $25^{\circ} \mathrm{C} / \mathrm{s}$ cooling rate 
deformation degree. Samples with the same deformation degree sustain a decrease in the volume fraction of the retained austenite as the cooling rate increases. The results are consistent with that the slower cooling rate results in a larger amount of the retained austenite [34], whereas a higher degree of hot deformation is generally found to decrease the volume fraction of the retained austenite [35].

\section{Conclusions}

1. The critical cooling rate of the B1500HS steel for a full martensite formation is approximately $25{ }^{\circ} \mathrm{C} / \mathrm{s}$ and the deformation results in the CCT curve of B1500HS steel moving toward the left of the curve.

2. If the cooling rate is lower than the critical cooling rate, both the $\mathrm{Bs}$ and $\mathrm{Mf}$ temperatures rise as the deformation degree increases but the Ms temperature is reduced.

3. In samples with the same cooling rate, the deformation of the B1500HS boron steel at the elevated temperature can refine the grain size of the austenite. An increase of the deformation degree leads to continuous size lessening of the transformed martensite and bainite phases due to austenite refinement.

4. At the same cooling rate, the micro-hardness of B1500HS boron steel decreases with an increase of the deformation degree.

5. The retained austenite in the B1500HS samples decreases as the deformation degree or cooling rate increase.

Acknowledgements This work was financially supported by the National Natural Science Foundation of China (Nos. 51175302, 51575324), and the Science and Technology Development Program of Shandong and Huangdao (Nos. 2014GGX103024, 20140132).

\section{References}

[1] L. Komgrit, H. Hamasaki, R. Hino, F. Yoshida, Elimination of springback of high-strength steel sheet by using additional bending with counter punch. J. Mater. Process. Technol. 229, 199-206 (2016). doi:10.1016/j.jmatprotec.2015.08.029

[2] H. Karbasian, A.E. Tekkaya, A review on hot stamping. J. Mater. Process. Technol. 210, 2103-2118 (2010). doi:10. 1016/j.jmatprotec.2010.07.019

[3] J. Min, J. Lin, J. Li, W. Bao, Investigation on hot forming limits of high strength steel 22MnB5. Comput. Mater. Sci. 49, 326-332 (2010). doi:10.1016/j.commatsci.2010.05.018

[4] H. Li, L. He, G. Zhao, L. Zhang, Constitutive relationships of hot stamping boron steel B1500HS based on the modified Arrhenius and Johnson-Cook model. Mater. Sci. Eng., A 580, 330-348 (2013). doi:10.1063/1.4806961

[5] H. Li, C. Wang, L. He, C. Zhang, Effect of heating and mold temperature on the mechanical properties and microstructure of
B1500HS boron steel. Mater. Perform. Charact. 6(1), 17-32 (2017). doi:10.1520/MPC20160108

[6] M. Merklein, J. Lechler, T. Stoehr, Investigations on the thermal behavior of ultra high strength boron manganese steels within hot stamping. Int. J. Mater. Form. 2, 259-262 (2009). doi:10. 1007/s12289-009-0505-X

[7] J. Cui, G. Sun, J. Xu, X. Huang, G. Li, A method to evaluate the formability of high-strength steel in hot stamping. Mater. Des. 77, 95-109 (2015). doi:10.1016/j.matdes.2015.04.009

[8] P. Hein, J. Wilsius, Status and innovation trends in hot stamping of USIBOR 1500P. Steel Res. Int. 79, 85-91 (2008). doi:10. 1002/srin.200806321

[9] M. Maikranz-Valentin, U. Weidig, U. Schoof, H.H. Becker, K. Steinhoff, Components with optimised properties due to advanced thermomechanical process strategies in hot sheet metal forming. Steel Res. Int. 79, 92-97 (2008). doi:10.1002/ $\operatorname{srin} .200806322$

[10] H. Li, L. He, C. Zhang, H. Cui, Research on the effect of boundary pressure on the boundary heat transfer coefficients between hot stamping die and boron steel. Int. J. Heat Mass Trans. 91, 401-415 (2015). doi:10.1016/j.ijheatmasstransfer. 2015.07.102

[11] S. Denis, E. Gautier, A. Simon, G. Beck, Stress-phase-transformation interactions-basic principles, modelling and calculation of internal stresses. Mater. Sci. Technol. 1, 805-814 (1985). doi: $10.1179 / \mathrm{mst} .1985 .1 .10 .805$

[12] A. Barcellona, D. Palmeri, Effect of plastic hot deformation on the hardness and continuous cooling transformations of 22MnB5 microalloyed boron steel. Metall. Mater. Trans. A 40, 1160-1174 (2009). doi:10.1007/s11661-009-9790-8

[13] M. Naderi, W. Bleck, An investigation into martensitic transformation in hot stamping process. WIT Trans. Eng. Sci. 57, 95-104 (2007). doi:10.2495/MC070101

[14] M. Nikravesh, M. Naderi, G.H. Akbari, Influence of hot plastic deformation and cooling rate on martensite and bainite start temperatures in 22MnB5 steel. Mater. Sci. Eng., A 540, 24-29 (2012). doi:10.1016/j.msea.2012.01.018

[15] A.J. Craven, K. He, L.A.J. Garvie, T.N. Baker, Complex heterogeneous precipitation in titanium-niobium microalloyed Al-killed HSLA steels-I. $(\mathrm{Ti}, \mathrm{Nb})(\mathrm{C}, \mathrm{N})$ particles. Acta Mater. 48, 3857-3868 (2000). doi:10.1016/S1359-6454(00)00194-4

[16] J.D. Verhoeven (ed.), Steel Metallurgy for the Non-metallurgist (ASM International, Novelty, 2007)

[17] K.F. Starodubov, Heat treatment of low carbon steel. Metal Sci. Heat Treat. 7, 453-454 (1966)

[18] S. Morito, Y. Adachi, T. Ohba, Morphology and crystallography of sub-blocks in ultra-low carbon lath martensite steel. Mater. Trans. 50, 1919-1923 (2009). doi:10.2320/matertrans. mra2008409

[19] S. Morito, X. Huang, T. Furuhara, T. Maki, N. Hansen, The morphology and crystallography of lath martensite in alloy steels. Acta Mater. 54, 5323-5331 (2006). doi:10.1016/j. actamat.2006.07.009

[20] P.M. Kelly, A. Jostsons, R.G. Blake, The orientation relationship between lath martensite and austenite in low carbon, low alloy steels. Acta Metall. Mater. 38, 1075-1081 (1990). doi:10.1016/ 0956-7151(90)90180-O

[21] S. Morito, H. Tanaka, R. Konishi, T. Furuhara, T. Maki, The morphology and crystallography of lath martensite in $\mathrm{Fe}-\mathrm{C}$ alloys. Acta Mater. 51, 1789-1799 (2003). doi:10.1016/S13596454(02)00577-3

[22] H. Kitahara, R. Ueji, M. Ueda, N. Tsuji, Y. Minaminoa, Crystallographic analysis of plate martensite in Fe-28.5 at.\% Ni by FE-SEM/EBSD. Mater. Charact. 54, 378-386 (2005). doi:10. 1016/j.matchar.2004.12.015 
[23] S. Morito, H. Yoshida, T. Maki, X. Huang, Effect of block size on the strength of lath martensite in low carbon steels. Mater. Sci. Eng., A 438, 237-240 (2006). doi:10.1016/j.msea.2005.12. 048

[24] Y.L. Zhao, J. Shi, W.Q. Cao, M.Q. Wang, G. Xie, Effect of direct quenching on microstructure and mechanical properties of medium-carbon Nb-bearing steel. J. Zhejiang Univ. Sci. A 11, 776-781 (2010). doi:10.1631/jzus.A1000147

[25] K.S. Kim, L.X. Du, C.R. Gao, Influence of vanadium content on bainitic transformation of a low-carbon boron steel during continuous cooling. Acta Metall. Sin. 28, 692-698 (2015). doi:10.1007/s40195-015-0249-1

[26] D.Q. Bai, S. Yue, T.M. Maccagno, J.J. Jomas, Effect of deformation and cooling rate on the microstructures of low carbon Nb-B steels. ISIJ Int. 38, 371-379 (1998). doi:10.2355/ isijinternational.38.371

[27] H. Li, K. Gai, L. He, C. Zhang, H. Cui, M. Li, Non-isothermal phase-transformation kinetics model for evaluating the austenization of 55CrMo steel based on Johnson-Mehl-Avrami equation. Mater. Des. 92(731-741), 2015 (2016). doi:10.1016/j. matdes. 12.110

[28] P. Maynier, J. Dollet, P. Bastien, Hardenability Concepts with Applications to Steels (AIME, New York, 1978), pp. 518-544

[29] H. Li, G. Zhao, S. Niu, C. Huang, FEM simulation of quenching process and experimental verification of simulation results. Mater. Sci. Eng., A 452-453, 705-714 (2007). doi:10.1016/j. msea.2006.11.023
[30] M. Abbasi, M. Naderi, A. Saeed-Akbari, Isothermal versus nonisothermal hot compression process: a comparative study on phase transformations and structure-property relationships. Mater. Des. 45, 1-5 (2013). doi:10.1016/j.matdes.2012.08.062

[31] M. Abbasi, A. Saeed-Akbari, M. Naderi, The effect of strain rate and deformation temperature on the characteristics of isothermally hot compressed boron-alloyed steel. Mater. Sci. Eng., A 538, 356-363 (2012). doi:10.1016/j.msea.2012.01.060

[32] J. Min, J. Lin, Y. Min, Effect of thermo-mechanical process on the microstructure and secondary-deformation behavior of 22MnB5 steels. J. Mater. Process. Technol. 213, 818-825 (2013). doi:10.1016/j.jmatprotec.2012.12.012

[33] R.M. Wu, W. Li, C.L. Wang et al., Stability of retained austenite through a combined intercritical annealing and quenching and partitioning (IAQP) treatment. Acta Metall. Sin. 28, 386-393 (2015). doi:10.1007/s40195-015-0217-9

[34] N.R.V. Bangaru, A.K. Sachdev, Influence of cooling rate on the microstructure and retained austenite in an intercritically annealed vanadium containing HSLA steel. Metall. Mater. Trans. A 13, 1899-1906 (1982). doi:10.1007/BF02645933

[35] H.B. Ryu, J.G. Speer, J.P. Wise, Effect of thermomechanical processing on the retained austenite content in a $\mathrm{Si}-\mathrm{Mn}$ transformation-induced-plasticity steel. Metall. Mater. Trans. A 33, 2811-2816 (2002). doi:10.1007/s11661-002-0266-3 